\title{
An Experiment in Semi-automated Spray Fireproofing
}

\author{
Iwao UCHIZAKI $^{\circ}$ and Yasuaki UCHIDA $^{\mathrm{b}}$
}

a. Construction Equipment Unit, Technical Research Laboratory, TAKENAKA Corporation, 2-5-14, Minamisuna, Koto-ku, Tokyo 136, JAPAN

b. Development Department, ASK Corporation, 2-5-5, Turumichuou, Turumi-ku, Yokohama 230, JAPAN

\begin{abstract}
Fireproofing material spraying is one of the labor intensive construction works under inferior working environment. Toward improvement of the working surroundings as well as the work efficiency, a semi-automatic fireproof material spraying robot has been experimentally constructed. It features a double-nozzle design and a man-machine cooperative system. Small-scale spraying tests were carried out with the prototype. The tests indicated that the following ideas can provide a guide to the development of construction robots:

1) Complex mechanisms and advanced control functions can be eliminated by adopting a man-machine cooperative system; this makes it possible to reduce the cost of the robot.

2) A robot can operate under heavy loads that would be difficult for humans, making it possible to raise work efficiency.
\end{abstract}

\section{Introduction}

In general, the fire resistance of structural steel members in buildings is ensured by applying fire-resistant material to them. About $30,000,000 \mathrm{~m}^{2}$ of fireproofing, in which the share of labor cost is $50 \%$, is carried out annually in Japan. In performing this work, workers manually operates nozzles which spray refractory material. While spraying, rock wool scatters and cementitious liquid splashes, creating an unhealthy work environment. This, coupled with the recent shortage of young or skilled laborers, has accelerated the introduction of automation technology into such a labor intensive 
task as fireproofing which has otherwise changed little over years.

Against this background, we have focused on a "wet" application method using factory prepared pre-packed material, mixed with water on site and spray through a slurry pump, nominal density of 500 $\mathrm{kg} / \mathrm{m}^{3}$. The reason is that the demand of this type of fireproofing work has been increasing with considerably high rate and will likely continue to increase. Although some spraying robots for the work have been developed using current automation technology, they have not yet found wide application. ${ }^{13}$

2. Basic outline of development

The following two drawbacks have generally been pointed out when replacing manual construction work with robot methods:

1) Higher cost

2) Lower work efficiency

To ensure that this would not be a problem in our case, we decided to improve the idea of simply replacing workers with robots. Put more precisely, we decided that in order to simplify the robots, they should not be designed to works suitable for humans(e.g. nozzle positioning or direction control), but only to do works that machines are good at (e.g. works that require power or speed). The conclusion drawn from discussions centering on the application of the philosophy to the automation of "wet"-type fireproofing spray work was that the following systems are the most important, most feasible and most cost-effective for installation in a robot system:

1) A man-machine cooperative system based on a mechanical balancer

2) A multi-nozzle sweep system

3. Element performance test

Figure 3.1 shows a prototype fireproofing machine designed at the initial stage of development. A multi-nozzle sweep mechanism and a

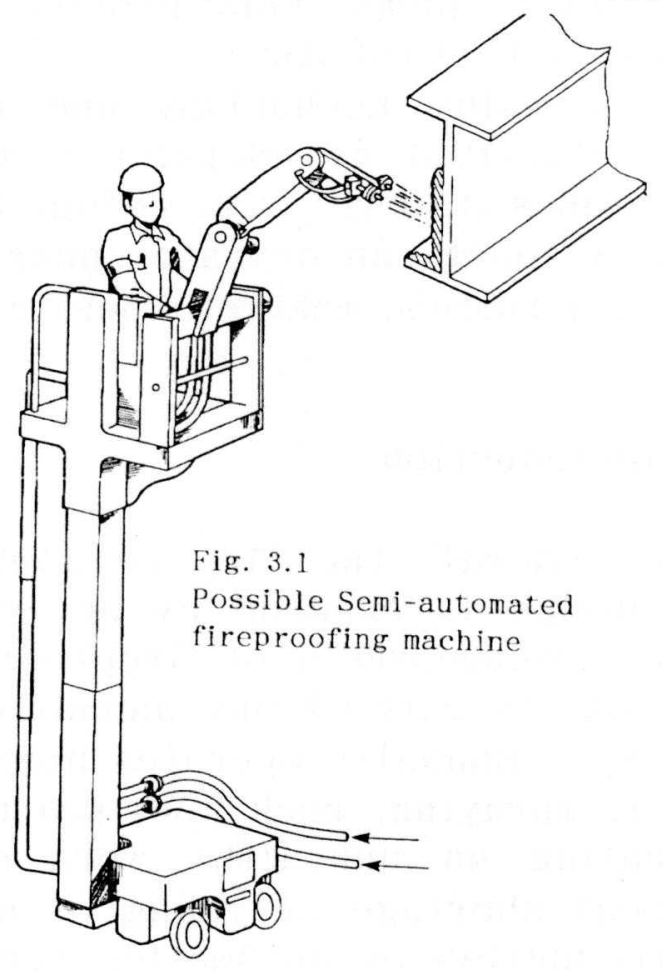


mechanical balancer mounted on a vehicle capable of high lift work are conceptually presented. To obtain appropriate design information for the prototype machine, a series of performance tests are
conducted.

\subsection{Experiments on nozzle system}

To investigate various designs for the multi-nozzle system, tests using a single nozzle were carried out. As a control, tests of manual spraying by workers were also performed.(See Photos 3.1 and 3.2.) The results of these tests can be summarized as follows.

1) A highly complicated mechanism is required to replace manually operated spraying nozzles.

2) Using a multi-nozzle design may increase the work efficiency, but it makes it difficult to form a uniform thickness layer. (In particular, the overlaps in batch spraying operations cause problems.)

3) A function which corrects for variations in the flow rate at a spray gun is required.

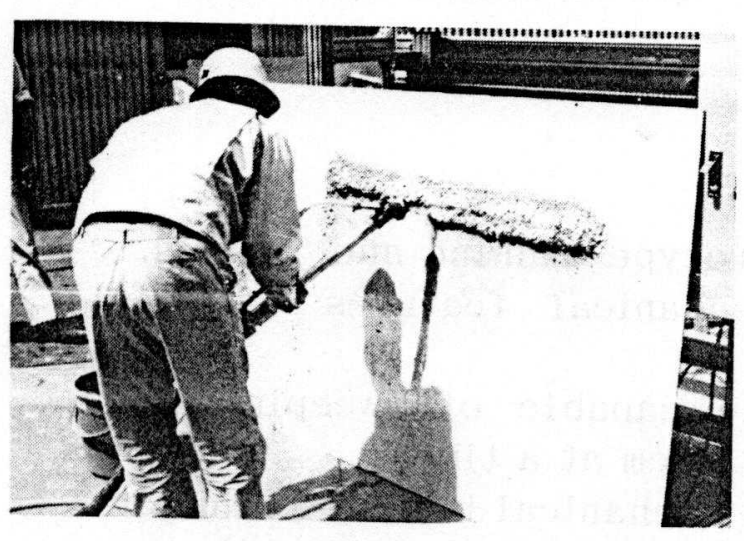

Photo 3.1 Manual Spraying

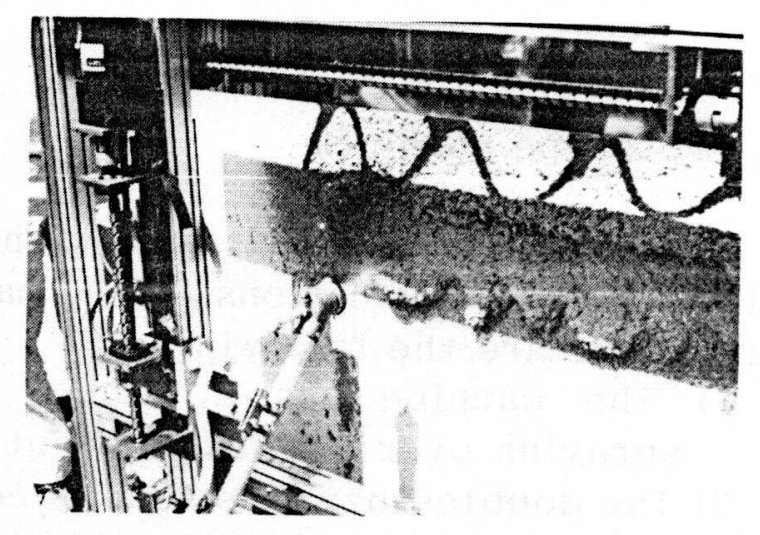

Photo 3.2 Mechanical Spraying

These results led us to select 1) a double-nozzle design and 2) a mechanism swinging parallel to the surface to be sprayed.

3.2 Experiments on vehicle for high lift work

The actual use of the machine was assumed to be limited to the following two methods:

1) A method in which the spraying position changes while the vehicle moves; that is, the worker's main task is to maneuver the vehicle.

2) A method in which the vehicle stops in a particular position and 
the spray nozzle is controlled manually with the aid of the balancer.

Method 1) above clearly requires a vehicle which can travel parallel to a structural beam at a constant speed with great accuracy. Both of the vehicle performance were tested using a commercially available multi-directional aerial work platform. Figure 3.2 and 3.3 show the test results. The linear travelling performance of the selected platform was within $25 \mathrm{~mm}$ per $5 \mathrm{~m}$ and the speed variation was less than $10 \%$ as shown in the figures, offering a performance suitable for our application.

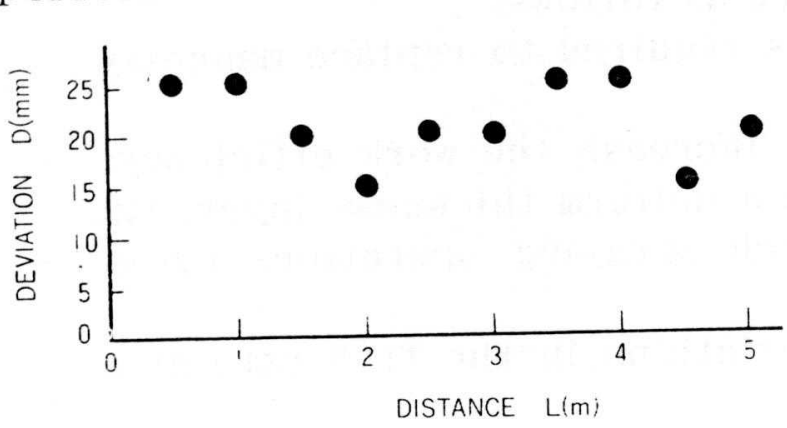

Fig.3.2 DEVIATION FROM A STRAIGHT COURSE

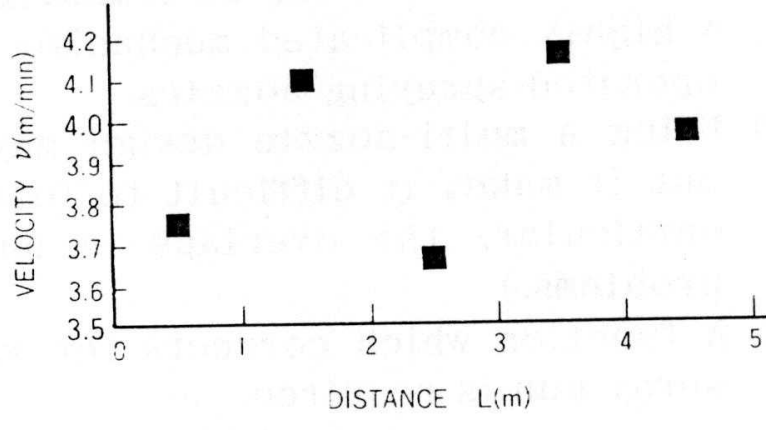

FIg.3.3 UNIFORMITY OF RUNNING SPEED

\section{Prototype machine}

Figure 4.1 and Photo 4.1 show the prototype machine and Table 4.1 gives its specifications. The main mechanical features of this prototype are the followings:

1) The machine has a double nozzle capable of sweeping and spraying over a width of about 40 to $50 \mathrm{~cm}$ at a time.

2) The double-nozzle is supported by a mechanical balancer and can be positioned and controlled by the operator with little effort.

3) The whole mechanism is mounted on a multi-directional aerial work platform.

This mechanism makes it possible to carry out the two types of spraying described above, spraying while the vehicle moving straight, and semi-automated spraying by a worker with the aid of the balancer while the vehicle stays put. The expectant area that can be sprayed per unit time is significantly increased by incorporating the double-nozzle design.

To maintain a constant distance between the nozzle and the surface being sprayed, a telescopic mechanism controlled by an ultrasonic distance sensor is also fitted. 


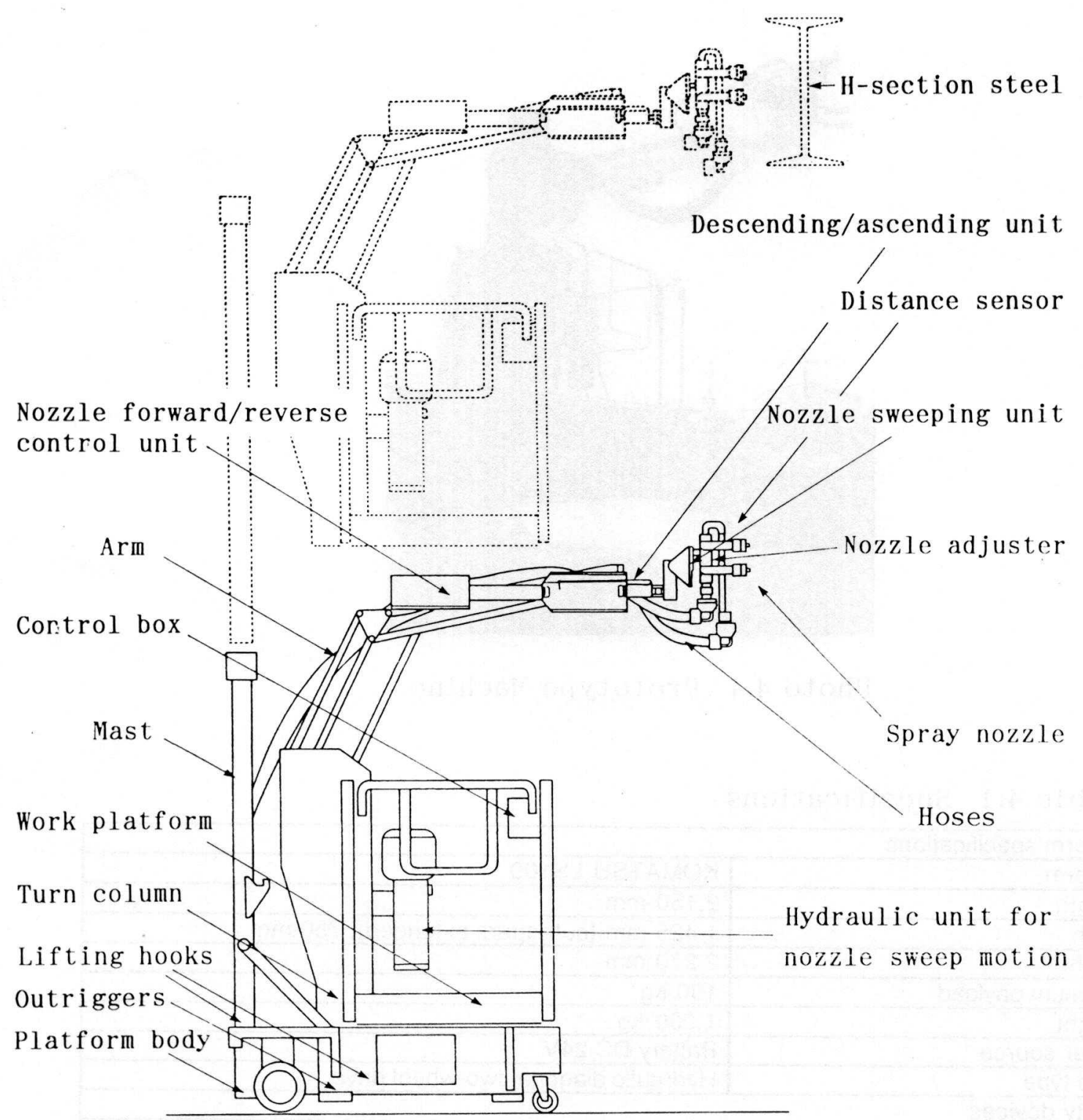

Fig. 4.1 Prototype Machine 


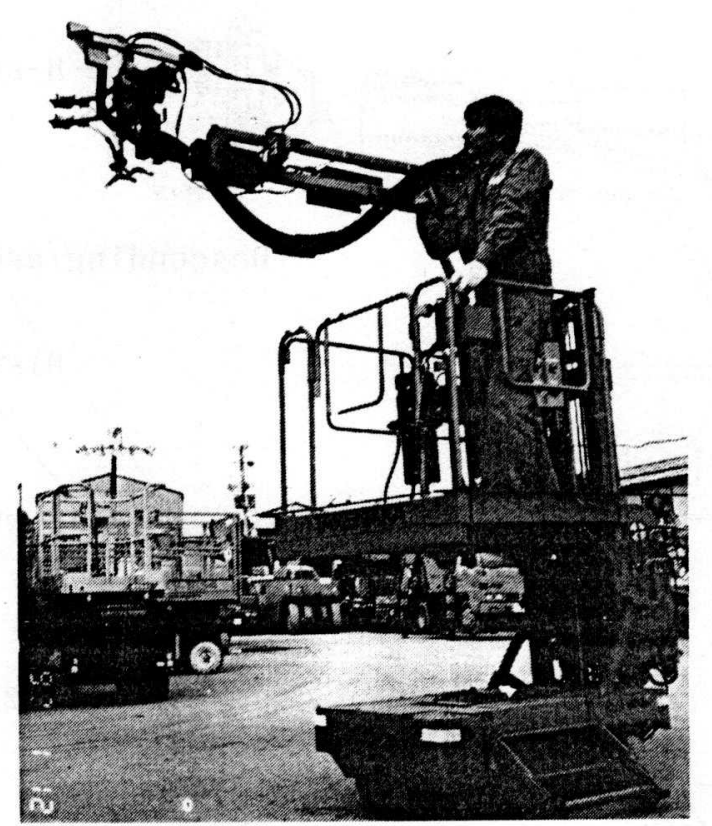

Photo 4.1 Prototype Machine

Table 4.1 Specifications

\begin{tabular}{|l|l|}
\hline Platform specifications & KOMATSU LS100 \\
\hline Platform & $2,150 \mathrm{~mm}$ \\
\hline Length & $1,425 \mathrm{~mm}$ (outriggers extended), $780 \mathrm{~mm}$ \\
\hline Width & $2,270 \mathrm{~mm}$ \\
\hline Height & $100 \mathrm{~kg}$ \\
\hline Maximum payload & $1,050 \mathrm{~kg}$ \\
\hline Weight & Battery DC 24V \\
\hline Power source & Hydraulic diagonal two-wheel drive \\
\hline Drive type & Overload alarm \\
\hline Safety devices & Emergency descent valve \\
\hline \multicolumn{2}{|l|}{} \\
\hline \multicolumn{2}{|l|}{} \\
\hline \multicolumn{2}{|l|}{ Emergency stop unit } \\
\hline Working performance & Inclination alarm \\
\hline Forward/backward distance & Travel limiters \\
\hline Travel speed & $440 \mathrm{~mm}$ (manually) \\
\hline Descending/ascending stroke & 0 to $6.7 \mathrm{~m} /$ min. \\
\hline Nozzle forward/backward stroke & $\begin{array}{l}4,650 ~ \mathrm{~mm} \text {, including descending stroke of work } \\
\text { platform }\end{array}$ \\
\hline Nozzle forward/backward speed & $280 \mathrm{~mm}$ (automatic) with ultrasonic distance sensor \\
\hline Nozzle forward/backward drive type & $870 \mathrm{~mm} / \mathrm{min}$. \\
\hline Nozzle inching rate & 0 to 150 cycles/min. \\
\hline Nozzle inching drive type & Hydraulic motor, AC 100V \\
\hline Nozzle sweeping & 90 degs. (manually) \\
\hline
\end{tabular}


5. Spray tests with the prototype

\begin{abstract}
A simple spraying test was carried out on an actual construction site in which fireproofing materials were applied to a wall using the prototype machine(See Photo 5.1). The purpose of the test was to investigate how much the spraying efficiency is improved by the double-nozzle design, as well as to acquire a qualitative comprehension of the advantages and disadvantages with regard to the semi-automated man-machine cooperative system.
\end{abstract}

The test results can be summarized as follows.

\section{1) Test under motion}

From the running test, which involved spraying while the vehicle was in motion, an instantaneous spray efficiency was obtained. This value represents the area sprayed per unit time, excluding all preparatory work. The value obtained was $1.1 \mathrm{~m}^{2} / \mathrm{min}$. almost double the record for manual spraying, which is $0.6 \mathrm{~m}^{2} / \mathrm{min}$. Figure 5.1 shows the thickness of the layer of fireproofing materials sprayed in the test.

\section{2) Fixed-vehicle-position test}

Spraying tests were carried out in which the double-nozzle was positioned by a worker while the vehicle was held in one position. The direction and position of the nozzle were controlled manually through a combination of the platform's descending motion and zero-weight positioning with the mechanical balancer. It is obvious that operator's workload was considerably lightened, and they got less tired than with conventional spraying work. Observations of the test indicate that even those deficient in physical strength could 
achieve intensive works with the aid of this automated unit. An uneven spray thickness resulted when the operator lacked skill, so we are now planning to investigate how this can be improved in the next step.

\section{Conclusions}

A semi-automatic fireproof material spraying robot has been experimentally constructed. It features a double-nozzle design and a man-machine cooperative system. Small-scale spraying tests were carried out with the prototype. The tests elucidated that the following ideas, conceived at the initial stage, can provide a guide to the development of construction robots;

1) Complex mechanisms and advanced control functions can be eliminated by adopting a man-machine cooperative system; this makes it possible to reduce the cost of the robot.

2) A robot can operate under heavy loads that would be difficult for humans, making it possible to raise work efficiency.

\section{References}

[1] H.Miyamoto, et al., "Development of System Capable of Spraying Fireproof Covering Materials," in Proceedings of the 9th International Symposium on Automation and Robotics in Construction, June 3-5, 1992. 